
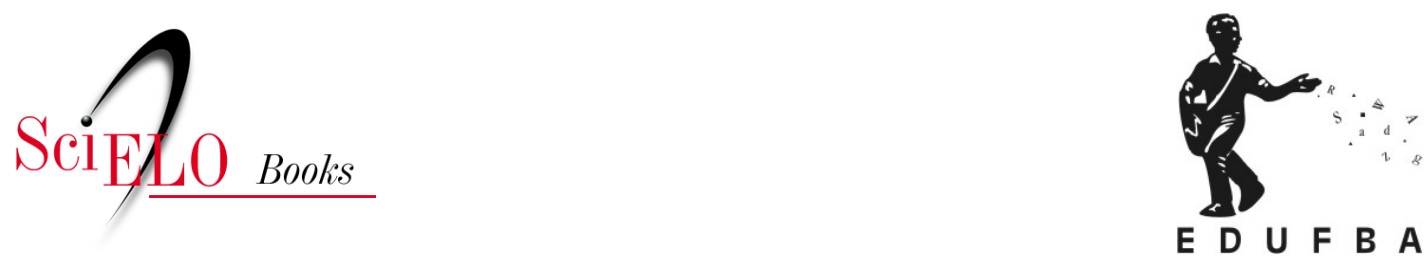

\title{
Parte II - Códigos Identitários e Alimentação Caridade para os Merecedores e Salvação para os Doadores: Sentidos da Comida Distribuída para a População em Situação de Rua
}

\author{
Julia Horta Nasser \\ Shirley Donizete Prado \\ Francisco Romão Ferreira \\ Daniela Menezes Neiva Barcellos
}

\section{SciELO Books / SciELO Livros / SciELO Libros}

NASSER, J. H., PRADO, S. D., FERREIRA, F. R., and BARCELLOS, D. M. N. Caridade para os Merecedores e Salvação para os Doadores: Sentidos da Comida Distribuída para a População em Situação de Rua. In: CARVALHO, M. C. V. S., KRAEMER, F. B., FERREIRA, F. R., and PRADO, S. D., eds. Comensalidades em trânsito [online]. Salvador: EDUFBA, 2020, pp. 245-266. Sabor metrópole series, vol. 11. ISBN: 978-65-5630-177-8.

http://doi.org/10.7476/9786556301778.0012.

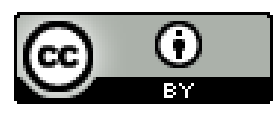

All the contents of this work, except where otherwise noted, is licensed under a $\underline{\text { Creative }}$ Commons Attribution 4.0 International license.

Todo o conteúdo deste trabalho, exceto quando houver ressalva, é publicado sob a licença Creative Commons Atribição 4.0.

Todo el contenido de esta obra, excepto donde se indique lo contrario, está bajo licencia de la licencia Creative Commons Reconocimento 4.0. 


\section{CARIDADE PARA OS MERECEDORES E SALVAÇÃO PARA OS DOADORES SENTIDOS DA COMIDA DISTRIBUÍDA PARA A POPULAÇÃO EM SITUAÇÃO DE RUA ${ }^{1}$}

JULIA HORTA NASSER

SHIRLEY DONIZETE PRADO

FRANCISCO ROMÃO FERREIRA

DANIELA MENEZES NEIVA BARCELLOS

\section{SÃo MUITOS OS INTERESSES, VALORES E SENTIDOS DEPOSITADOS NA COMIDA QUE É SERVIDA “DE GRAÇA”}

Ao transitar a noite pelo centro da cidade do Rio de Janeiro, observa-se um grande número de instituições e organizações, religiosas ou não, distribuindo comida e roupas para as pessoas que se encontram em situação de rua e habitam aquele local. Na maioria das vezes, o alimento ali distribuído corresponde a única refeição que aquelas pessoas fazem no dia.

1 Texto desenvolvido a partir da dissertação de mestrado acadêmico intitulada O que comem os excluídos? Os diferentes sentidos da comida oferecida para a população em situação de rua defendida no ano de 2018, no Programa de Pós-Graduação em Alimentação, Nutrição e Saúde da Universidade do Estado do Rio de Janeiro (UERJ). O presente trabalho foi realizado com o apoio da Coordenação de Aperfeiçoamento de Pessoal de Nível Superior (Capes) - Código de Financiamento 001. 
É interessante notar que as diversas instituições que fazem esse tipo de trabalho lidam de formas diferentes com a questão da alimentação: algumas só oferecem a comida e não estabelecem contato algum com o assistido; outras oferecem a comida junto aos serviços, em ações sociais; há as que condicionam a doação da comida à participação dessas pessoas a algum culto religioso ou oração na rua; há, ainda, as que oferecem a comida juntamente com yoga e meditação; entre outras possibilidades. A forma como cada uma dessas instituições e organizações vê a população em situação de rua e entende esse processo está relacionada com os sentidos atribuídos à comida oferecida a essas pessoas.

Buscando compreender as redes de sentido em torno das práticas de distribuição de comida para a população em situação de rua consideramos, neste ensaio, um conjunto bibliográfico, com destaque para abordagens etnográficas, além de documentos institucionais, páginas na internet e reportagens sobre a temática em questão. (NASSER, 2018)

O presente estudo está inscrito no campo científico da Alimentação e Nutrição. Entendemos campo no sentido atribuído por Pierre Bourdieu (1989), para quem existe uma espécie de poder simbólico que organiza as práticas e os discursos, cria formas de entendimento da realidade e dá sentido ao real.

Ao abordar a alimentação de pessoas em situação de rua colocamo-nos na interface da produção de saberes situada entre o estilo biomédico de pensar e as Humanidades. Em outras palavras, trata-se de uma opção que implica em delicada tensão entre campos científicos que fazem parte de uma rede ou um conjunto de relações objetivas definidas a partir das diferentes posições que os atores - sujeitos, agentes ou instituições - ocupam na atual estrutura da distribuição das diferentes espécies de poder - ou de capital.

O capital hoje, inerente aos estudos de cunho biomédico, traduz-se em uma posição hierárquica que busca a dominação em relação aos outros atores que participam do mesmo jogo. Contudo, o campo é concebido em seu dinamismo; ele é mutável. Refletindo a dinâmica das posições e das relações de poder próprias a cada campo coloca, simultaneamente, a recusa à subordinação, à dependência, à homologia. Expressando hierarquias que são estruturadas e ao mesmo tempo estruturantes das ações e que definem as relações no campo, o poder faz-se presente, toma forma no jogo, materializa-se também neste investimento situado no âmbito qualitativo da 
compreensão das redes de sentido em torno das práticas de distribuição de comida para a população em situação de rua. Poder que possibilita registrar a distribuição de comida, para além dos aspectos nutricionais, entendida como capital em jogo hirto, retesado, tanto para quem recebe, quanto para quem doa, uma vez que essa doação transforma-se em moeda simbólica nas trocas subjetivas do campo social.

Isso porque a comida faz do alimento algo além de veículo. Possui a função objetiva de carregar os nutrientes e que está situado na ordem da natureza, no plano biológico ou bioquímico; a comida é o alimento simbolizado que está na ordem da cultura. Nessa diferenciação conceitual, quando comemos, incorporamos tanto elementos biológicos quanto os aspectos culturais daquilo que ingerimos. Dentro dessa perspectiva, comer é mais que um ato de sobrevivência, é uma prática simbólica e cultural. Então, oferecer comida à população em situação de rua não é apenas um gesto para saciar a fome biológica.

Doar comida e comer essa comida corresponde a uma ação que pode ter outras implicações além daquelas da esfera nutricional, pois quem capitaliza nesse jogo não são apenas os moradores de rua: demais atores sociais e instituições também se alimentam dos benefícios, dos sentidos gerados pelas doações. (CARVALHO; LUZ; PRADO, 2011; CONTRERAS; GRACIA, 2011; SILVA et al., 2010) Afinal, de acordo com Max Weber (2010), toda ação possui um sentido. Como toda conduta humana - fazer externo ou interno, permissão ou omissão -, é dotada de um significado subjetivo por quem a executa e a orienta; sendo direcionada por um outro, Weber a denomina de ação social. Ao compreender uma ação social, captamos e interpretamos sua conexão de sentidos.

Entendemos, então, a distribuição de comida como uma relação social, pois a conduta de cada qual entre os múltiplos agentes envolvidos orienta-se por um conteúdo de sentido reciprocamente compartilhado. Se para receber comida é preciso, por exemplo, atender a alguma exigência, partilha-se essa exigência entre quem doa e quem recebe, havendo que se investir para conhecer os significados atribuídos a essas ações sociais pelos atores envolvidos. Na relação social, o conteúdo de sentido é incorporado pelos agentes como uma regra orientadora da sua conduta na medida em que é aceito como legítimo, tornando-se um sentido aceito e que assume a forma de validação de uma ordem legítima. (WEBER, 1977) 
Assim, o ato de comer e a ação de distribuir comida, por ser uma ação social possui um significado e um sentido compartilhado pelos atores sociais que participam do jogo, de forma consciente ou não. Esse sentido é produzido socialmente a partir das lógicas que regem o modo de organização social e das relações de poder-saber ali estabelecidas. Quando comemos, ingerimos também essas lógicas. Lógicas essas que também produzem identidades individuais e coletivas, subjetividades e a forma como esses sujeitos estabelecem relações sociais.

Mas a apropriação dos sentidos não se dá apenas no plano das relações entre sujeitos e coletividades que estão na rua; os sentidos são também apropriados, reproduzidos e ressignificados por instâncias institucionais que reafirmam suas práticas e criam estratégias de ação voltadas para os seus interesses. O capital simbólico oriundo da doação de comida extrapola a sua função local e gera ganhos em outras esferas no campo da política partidarizada, nas formas de atuação das políticas públicas, em esferas de atuação religiosa e nas ações de marketing social das empresas que participam indiretamente das ações. São muitos os interesses (políticos e econômicos), valores (religiosos e morais) e sentidos (do jogo simbólico da cultura) depositados na comida que é servida "de graça”.

\section{A PRODUÇÃO DE SENTIDOS E SUBJETIVIDADES EMTEMPOS DE EXCLUSÃO}

O contexto da existência em situação de rua nos convida a compreender os modos de operação das lógicas que constroem a realidade em uma dada sociedade, a produção dos sentidos atribuídos às ações e as subjetividades presentes no campo em estudo. Os conceitos de produção de subjetividade, de Guattari e Rolnik (2013), e de processos de subjetivação, de Foucault (2004a), nos permitem avanços consideráveis em relação a este tema.

Guattari e Rolnik (2013) definem subjetividade, ${ }^{2}$ como um fluxo contínuo de sensações, modos de existir, de imagens, sons, afetos, valores, etc. A subjetividade é fabricada e modelada no registro social, ou seja, no entrecruzamento de instâncias sociais, técnicas, institucionais e individuais - a partir de

2 Guattari e Rolnik (2013) preferem se utilizar do termo subjetividade ao invés do termo sujeito, para ressaltar o caráter dinâmico que eles querem imprimir ao conceito. 
máquinas que forjam maneiras de ser, estar e viver. Essas máquinas produzem a maneira que o indivíduo "[...] percebe o mundo, de se articular com o tecido urbano, com os processos maquínicos do trabalho, e com a ordem social suporte dessas forças produtivas” (GUATTARI; ROLNIK, 2013, p. 34) e variam em função ao modelo de organização de uma sociedade.

As lógicas que regem uma dada sociedade produzem as subjetividades ali presentes. Quando esses modelos de organização seguem lógicas normatizantes e serializantes, dizemos que as subjetividades ali produzidas são assujeitadas, são esquadrinhadas, ou seja, encaixadas em maneiras preexistentes de ser. (BAREMBLIT, 1994; GUATTARI; ROLNIK, 2013) Os movimentos que esquadrinham, bloqueiam os processos de produção de subjetivação "[...] não assujeitada, primigênica, produtiva, revolucionária, em que o desejo se realiza em conexões locais, micro e se efetua gerando o novo”. (BAREMBLIT, 1994, p. 51) Podemos observar que duas lógicas principais regem os processos de produção de subjetividade, as lógicas normatizadoras, maquínicas, que esquadriam as subjetividades na tentativa de adequá-las às subjetividades existentes; e lógicas singularizantes, que produzem subjetividades a partir dos processos criativos de produção.

Sobre os processos de subjetivação, segundo Foucault (2004a), os sujeitos são formados a partir das relações de poder-saber em uma dada sociedade. Definimos Saber, dentro de uma perspectiva foucaultiana, como um conjunto de elementos - objetos, tipos de formulação, conceitos e escolhas teóricas - formado a partir de uma única e mesma positividade, no campo de uma formação discursiva. Já em relação ao conceito de poder, Foucault (1989) se opõe a noção de um poder de submissão maciço e homogêneo de um indivíduo, classes, grupos, sobre outros, que pode ser dividido entre aqueles que o possuem e o detêm exclusivamente e aqueles que são submetidos a ele, tal qual descrito no poder-soberano - uma das formas de se exercer o poder. Para o autor, o poder é circulante, funciona em cadeia, se exercendo em rede. Na sua teia, os indivíduos circulam podendo num determinado momento exercer o poder e no outro sofrer a sua ação. Foucault (1988) discute em suas obras sobre o poder como um conjunto de relação, “relações de poder”. Sobre isso, nos diz:

[...] o poder não é algo que se adquire, arrebate ou compartilhe, algo que se guarde ou deixe escapar; o poder se exerce a partir 
de inúmeros pontos e em meio a relações desiguais e móveis; as relações de poder não se encontram em posição de exterioridade com respeito a outros tipos de relações - processos econômicos, relações de conhecimento, relações sexuais -, mas lhe são imanentes a estes; elas são os efeitos imediatos das divisões, desigualdades e desequilíbrios que ocorrem nestes outros tipos e, inversamente, são as condições internas dessas diferenciações; as relações de poder, não estão em posição superestruturais, tendo meramente um papel de proibição ou acompanhamento; elas têm um papel produtivo, onde quer que entre em ação; o poder vem de baixo; isto é, não há, no princípio das relações de poder, e como matriz geral, uma oposição binária e global entre os dominadores e os dominados, dualidade que repercute de alto a baixo e sobre grupos cada vez mais restritos até as profundezas do corpo social [...]; as relações de poder são, ao mesmo tempo, intencionais e não subjetivas. Se, de fato, são inteligíveis, não é porque sejam efeito, em termos de causalidade, mas porque atravessadas de fora a fora por um cálculo: não há poder que se exerça sem uma série de miras e objetivos. Mas isso não quer dizer que resulte da escolha ou da decisão de um sujeito, individualmente [...]. (FOUCAULT, 1988, p. 104-105)

Voltando aos processos de subjetivação, a maneira de ser e estar em sociedade é construída num processo diretamente relacionado com os saberes próprios daquele contexto histórico-cultural que por sua vez respondem por relações de poder em curso. Quando os conhecimentos sobre determinados assuntos vão sendo produzidos, juntamente com eles vão sendo gerados sujeitos. (FOUCAULT, 2004a; OKSALA, 2011)

O conceito de governamentalidade de Foucault também é importante para a discussão aqui proposta. $\mathrm{O}$ autor utiliza esse termo para se referir ao estudo da maneira de se governar. Foucault traz duas ideias principais para a noção de governamentalidade. A primeira está relacionada a governamentalidade política, que é formada por racionalidades, instrumentos técnicos - dispositivos de segurança, tecnologia político-militar e poder de polícia - e formas de instrumentalização do Estado para o governo dos corpos. A segunda noção refere-se ao encontro das técnicas de dominação e controle e o governo de si. Dentro dessa perspectiva o poder emana através do Estado, tal qual escrita na governamentalidade política, mas se espraia, dissemina, pela vida social, criando mecanismos de regulamentação 
da população. (FOUCAULT, 2012) Segundo Foucault(2012, p. 283), “[...] a soberania não se exerce sobre as coisas, ela se exerce primeiro sobre um território, e, por conseguinte, sobre os sujeitos que nele habitam".

Nessa perspectiva, não se trata apenas de controlar o território e as relações políticas e econômicas, mas, principalmente, governar os corpos, corações e mentes, disciplinar os corpos a partir de um controle disciplinar e um conjunto de regras, valores e sentidos que mantenham a governamentalidade. Para demonstrar essas diferentes formas de governar os corpos e o governo de si, Foucault lança mão do que ele chama de tecnologia de poder. $\mathrm{O}$ autor, na sua obra, apresenta três tecnologias de poder: soberano, disciplinar e a biopolítica. Apesar dessas três tecnologias de poder emergirem em momentos distintos da história da humanidade, o surgimento de uma não exclui e nem suprime a anterior, nem suas técnicas, ela a integra e a modifica. $\mathrm{O}$ preconceito generalizado com a população em situação de rua atualiza e naturaliza uma posição política que produz normas disciplinares as quais enquadram os corpos da população de rua e um olhar médico que tenta higienizar, promover uma espécie de eugenia ao tentar retirar os corpos considerados sujos, indesejáveis, perigosos e nocivos ao bem-estar do conjunto da sociedade. Mas, não podemos esquecer que são corpos os quais nos apresentam as consequências da desigualdade social, da exploração econômica e da exclusão do mundo do trabalho.

A retirada dessa população, majoritariamente negra, dos lugares de grande circulação de turistas na cidade nos períodos dos grandes eventos recentes - Rio+20, Copa do Mundo, Olimpíadas etc. - é um exemplo dessa convergência entre segurança pública, saberes médicos, higienização dos corpos, estratégias de controle disciplinar, normatização da população e regulamentação do uso do espaço público. Tudo em nome da higiene, da segurança, da saúde e do controle do Estado sobre a população pobre. Os saberes médicos assumem então um papel fundamental nessa limpeza social, nessa higienização dos corpos indisciplinados ou não adaptados ao sistema produtivo que ameaçam a segurança do conjunto da sociedade e não obedecem às normas vigentes, pois o conjunto constituído por medicina, segurança pública e higiene apresentam

[...] o vínculo que se estabelece entre as influências científicas sobre os processos biológicos e orgânicos (isto é, sobre a popu- 
lação e sobre o corpo) e, ao mesmo tempo, na medida em que a medicina vai ser uma técnica política de intervenção, com efeitos de poder próprios. A medicina é um poder-saber que incide ao mesmo tempo sobre o corpo e sobre a população, sobre o organismo e sobre os processos biológicos e que vai, portanto, ter efeitos disciplinares e efeitos regulamentadores. (FOUCAULT, 2002, p. 302)

O poder soberano, a sociedade da soberania tem como um dos seus atributos fundamentais o direito de vida ou morte, ou seja, o direito de fazer morrer ou deixar viver. O exercício de poder girava em torno do Rei ou príncipe, o soberano, sobre seus súditos. Todo crime era percebido como ataque à própria pessoa do soberano. $\mathrm{O}$ castigo era sempre mais brutal que o crime e servia como exemplo a não ser seguido aos demais. O ápice do exercício do poder soberano se dava no suplício, ou seja, castigos físicos sobre o corpo do condenado.(FOUCAULT, 2002, 2008) A morte do outro, daquele que é considerado indigno, improdutivo ou incapaz de gerir a própria vida torna-se então "natural", fazendo com o que os preconceitos de raça, de classe ou de etnia se afirmem e justifiquem a "limpeza social", ao eliminar da vista, ou da vida, os seres que são considerados indesejáveis ou perigosos. Segundo Foucault (2002, p. 309), o racismo

[...] assegura a função de morte na economia do biopoder, segundo o princípio de que a morte dos outros é o fortalecimento biológico da própria pessoa na medida em que ela é membro de uma raça ou uma população unitária e viva. [...] A especificidade do racismo moderno, o que faz sua especificidade, não está ligada a mentalidades, a ideologias, a mentiras do poder. Está ligada à técnica do poder, à tecnologia do poder. [...] Portanto, o racismo está ligado ao funcionamento de um Estado que é obrigado a utilizar a raça para exercer o seu poder, a eliminação das raças e a purificação da raça para exercer o seu poder soberano.

A segunda tecnologia de poder descrita por Foucault é o poder disciplinar/sociedade disciplinar. Seu principal dispositivo é a disciplina e seu principal foco é tornar os corpos dóceis e úteis para o trabalho. As disciplinas são um conjunto de procedimentos, técnicas, estratégias, que têm o corpo como alvo de seu exercício, da sua política de correção. (FOUCAULT, 2008) 
Nessa perspectiva, o poder disciplinar não aceita uma população empobrecida, que não gera riqueza, que atrapalha o bom funcionamento da ordem pública, que não segue as normas de higiene e conduta ditas "normais". E o corpo que não segue suas lógicas não tem seus direitos respeitados. O poder disciplinar, portanto, segrega, exclui e dificulta a circulação dos corpos considerados indisciplinados.

A terceira e última tecnologia de poder descrita por Foucault é a biopolítica. A biopolítica se dirige não ao homem corpo e, sim, ao homem ser vivo, ou seja, a massa global, a população. Tem como foco "fazer viver e deixar morrer”. (FOUCAULT, 2002, p. 202) A biopolítica é um conjunto de processos que lidam com as práticas regulatórias dos fenômenos que são coletivos. O poder disciplinar está relacionado à acomodação de mecanismos de poder sobre os corpos individuais, como a vigilância e o treinamento, dentro de um conjunto de técnicas chamada de disciplina. Já a biopolítica está relacionada ao conjunto de processos que produzem mecanismos regulatórios. O poder aqui não é o da lei, e sim da norma. Norma essa que não vai apenas reprimir os sujeitos, mas o constituir, tal qual explicado anteriormente nos processos de subjetivação. O corpo precisa ser disciplinado e a população precisa ser regulada. Por fim, dá-se o nome de biopoder a junção do poder disciplinar e da biopolítica.

É importante ressaltar que os mecanismos da biopolítica são muito mais sutis que os mecanismos de poder do poder disciplinar. Aqui as práticas regulatórias são internalizadas por cada sujeito, no que o autor chama de governo de si, ou técnicas de cuidado de si. A população, a sociedade, não precisa de um objeto concreto, tal qual o panóptico, que lembre o que devemos ou não fazer. É a partir da internalização das normas, leis, saberes, controles das estratégias que, em liberdade, relacionamo-nos com os outros e cada um de nós consigo mesmo. É dentro dessa perspectiva que Foucault afirma que podemos analisar as técnicas de governos dos outros, ao analisar as técnicas de governo de si. (REVEL, 2011)

Como veremos a seguir, o sujeito que vive sua trajetória de vida nas ruas, constrói sua forma de ser e estar no mundo, numa lógica diferente das lógicas ditas “normais” em nossa sociedade. E muitas das ações de distribuição de comida para a população em situação de rua tentam adequar esse grupo populacional a essas tais lógicas normatizantes e serializantes, produzindo assim subjetividades assujeitadas, nessa tentativa de transformá-los 
em corpos dóceis e úteis para o trabalho. Mas antes de entrar nessa seara, apresentaremos a população em situação de rua, grupo foco dessas ações.

\section{OS EXCLUÍDOS: POPULAÇÃO EM SITUAÇÃO DE RUA}

Quando andamos pela cidade, no corre-corre da vida, quase não percebemos população em situação de rua. Na maioria das vezes, misturam-se na paisagem das grandes cidades. Notamos sua presença quando, de alguma forma, nos incomodam, seja pela sujeira, pelo odor que emitem, por um pedido impertinente, pelo medo, pela compaixão, mas, de uma forma geral, não observamos a sua presença. "Mendigos”, “loucos”, ““alcoólatras”, “"vagabundos”, “ladrões”, ““sujos”, ““cracudos”, “"perigosos”, ““coitados”, muitos são os adjetivos atribuídos para as pessoas que vivem parte de suas trajetórias de vida nas ruas. Eles ficam como que invisibilizados do jogo social por não participarem do mercado, do mundo produtivo do trabalho e dos códigos sociais padronizados e legitimados pela cultura hegemônica.

Podemos definir população em situação de rua como grupo social heterogêneo, sujeitos com laços familiares e comunitários fragilizados ou rompidos e que, por não terem moradia e, na maioria dos casos, nem emprego formal, utilizam a rua, albergues e abrigos como local de moradia de forma provisória ou permanente. Estamos tratando de um fenômeno social complexo, que tem a exclusão social e econômica como principal fator de produção, reprodução e agravamento dessa situação. (BOVE; FIGUEIREDO, 2014)

O fenômeno social "população em situação de rua” é antigo, acentuado em face das transformações sociais e econômicas decorrentes do advento das sociedades pré-industriais da Europa, do capitalismo industrial e o fortalecimento dos grandes centros urbanos que culminaram na Revolução Industrial e Agrícola na segunda metade do século XVIII. No Brasil, o fenômeno surge desde antes do Império, com as constantes migrações das regiões norte e nordeste para os municípios mais desenvolvidos. A abolição da escravatura também foi um importante marco para o aumento de pessoas em situação de rua. Em nosso país, a população de rua tem cor e ela é majoritariamente negra. (BOVE; FIGUEIREDO, 2014)

São inúmeros os motivos que levam as pessoas a viver parte da suas trajetórias de vidas nas ruas e isso produz umas das principais marcas desse segmento populacional: a heterogeneidade. Atualmente, o termo técnico 
usado para designar esse grupo populacional é “população em situação de rua”. Estar em situação de rua não significa vivenciar uma situação estática e linear; são grupos que transitam, trabalham e moram na rua por diversos motivos. A rua, em diferentes graus, ocupa um lugar de referência e um papel central em suas vidas. (NAIFF, 2016)

Outra característica marcante desse grupo populacional é a exclusão social. Esta exclusão social pode ser entendida como um fenômeno dinâmico com múltiplas dimensões: a vulnerabilidade nos vínculos no mundo do trabalho, nas dimensões sociofamiliar, política e humana - esta última que se caracteriza pela fragmentação dos laços entre os indivíduos, a sociedade e o Estado, na intensa privação material e na desqualificação desse sujeito enquanto humano e cidadão. Em geral, no senso comum, essas pessoas são vistas, cotidianamente, como algo que as aproxima da animalidade, colocando-as numa condição que as distancia das características que traduzem sua humanidade, gerando preconceito, essa marca social que as inferioriza. Isso sem que se procure saber o mínimo que seja sobre as causas deste processo, as circunstâncias reais e as alternativas possíveis para solucionar o problema. O preconceito afasta e, muitas vezes, não permite sequer uma aproximação em caráter de ajuda humanitária.

Os processos relacionados à vulnerabilidade dos vínculos no mundo do trabalho são importantes para a produção da exclusão social. Essa fragilidade é induzida pelo modo de organização da sociedade capitalista, sendo um dos fatores principais de produção de "desnecessários humanos”, conforme conceito trabalhado por Bauman (2005). A dimensão sociofamiliar se caracteriza pelo distanciamento dos valores e das relações familiares e comunitárias, devido a alguma precariedade ou ruptura desses vínculos. Os elos sociais estabelecidos com a família e a comunidade, segundo Escorel (1999), tornam-se algumas das principais referências de reconhecimento de pertencimento e suporte frente às adversidades provenientes do mercado de trabalho e das inconsistências de políticas sociais. A exclusão ou, como diz a autora, a desvinculação no âmbito sociofamiliar, produz solidão e isolamento (parcial ou completo) e acarreta o não compartilhamento de um lugar social, devido à inexistência de ancoragem em uma unidade de pertencimento familiar ou comunitária. (ESCOREL, 1999)

A dimensão política da exclusão social está ligada à relação entre a pobreza e as situações de não exercício da cidadania. A cidadania constitui-se 
no direito de termos direito e o cidadão é aquele portador do direito legítimo, isto é, são sujeitos que possuem o poder de agir e falar e de serem ouvidos. O sujeito pode ser privado do direito a ser cidadão de algumas formas: no despotismo, no qual uma única pessoa tem direito; no caso de estrangeiros que vivem sob leis diferenciadas; nas situações sociais em que não há leis para determinado grupo populacional; e nas condições em que, embora haja leis para todos, o exercício do direito é dado a determinados grupos. O último caso está relacionado com a dimensão política da exclusão. (ARENDT, 1989; ESCOREL, 1999; WOLLZ et al., 2015)

Por fim, a dimensão humana da exclusão social que, de acordo com Escorel (1999, p. 81) "[...] pode atingir o seu limite, o limiar da existência humana” e que está relacionada com a redução desses grupos sociais excluídos à condição de labor. Em Hanna Arendt (2007), a condição humana, ela chama de vita activa, está relacionada a três atividades humanas fundamentais: labor, trabalho e ação. O labor corresponde aos processos biológicos, ao metabolismo e a satisfação das necessidades básicas, que nos mantém vivos, e que assegura a sobrevivência da espécie. O trabalho está associado à capacidade humana de produzir e fabricar o mundo que vivemos. Já a ação está relacionada com a habilidade dos homens interagirem; é o que nos dá a capacidade da construção das diferenças, da pluralidade. Enfim, o que nos dá a condição humana, para a autora, são essas três atividades fundamentais. $\mathrm{Na}$ exclusão social ocorre uma redução da atividade humana a condições de labor. Como efeito a ação humana passa a ser direcionada a manutenção das necessidades básica fundamentais, ou seja, a manutenção da vida biológica. (ARENDT, 2007; ESCOREL, 1999)

É nesses termos que tomamos as dimensões aqui citadas como produtoras desse fenômeno chamado exclusão social. Os grupos excluídos são, portanto, aqueles que, sem vínculo com o mundo do trabalho, sem possibilidade de exercer seus direitos, ou seja, cidadania, e cujos laços familiares e comunitários estão fragilizados ou rompidos, têm sua ação no mundo limitada à sua capacidade de sobrevivência. A esses classificamos como desnecessários, refugo, supérfluo à vida social. Sobre isso diz Escorel (1999, p. 81, grifo do autor):

A exclusão social pode se caracterizar não só pela extrema privação material, mas, principalmente, porque essa mesma privação material 'desqualifica' seu portador, no sentido de que lhe retira 
a qualidade de cidadão, de brasileiro (nacional), de sujeito e de ser humano, de portador, vontades e interesses legítimos que o identificam e diferenciam. A exclusão social significa o não encontrar nenhum lugar social, o não pertencimento a nenhum topos social, uma existência limitada à sobrevivência singular e diária. Mas ao mesmo tempo, o indivíduo mantém-se prisioneiro do próprio corpo. Não (mais) um lugar social para ele, mas ele deve encontrar formas de suprir suas necessidades vitais e sobreviver sem suporte estáveis materiais e simbólicos. A ausência de lugar envolve uma 'anulação' social, uma diferença desumanizadora, que reveste seu cotidiano com um misto de indiferença e hostilidade.

Uma outra marca importante da população em situação de rua são os estigmas que lhes são atribuídos em função de sua trajetória de vida, esses predicados que tornam o indivíduo diferente dos outros, reduzindo-o a uma pessoa diminuída ou estragada. A sociedade categoriza seus membros como comuns, naturais, normais e anormais de acordo com seus ambientes sociais, ou seja, suas rotinas e relações sociais, criando assim identidades sociais. (GOFFMAN, 1978)

Essas identidades sociais (reais ou virtuais), características e atributos individuais, são preconcepções construídas nos ambientes sociais transformadas em expectativas normativas, ou seja, em exigências apresentadas ao sujeito de modo rigoroso, afirmando aquilo que deveria ser. A condição necessária para a vida social é que todos os participantes compartilham um único conjunto de expectativas normativas. As normas precisam ser incorporadas por aqueles que compõe o grupo. Quando uma regra é quebrada surgem medidas restauradoras, seja por agências de controle, seja pelo próprio indivíduo. De uma forma geral, é destoante qualquer membro de um determinado grupo que não adira a norma, essas que engendram desvios e conformidades. São, então, desviantes sociais esses que não se comportam em conformidade com as normas tidas como legítimas.

O estigma envolve não tanto um conjunto de indivíduos concretos que podem ser divididos em duas pilhas, a de estigmatizados e a de normais, quanto um processo social de dois papéis no qual cada indivíduo participa de ambos, pelo menos em algumas conexões $e$ em algumas fases da vida. O normal e o estigmatizado não são pessoas, e sim perspectivas que são geradas em situações sociais 
durante os contatos mistos, em virtude de normas não cumpridas que provavelmente atuam sobre o encontro. (GOFFMAN, 1978, p. 177, grifo nosso)

Um dos efeitos desse processo social é a sensação de que os estigmatizados são imperfeitos, não são completamente humanos, gerando uma série de discriminações que reduzem suas chances de vida ao produzir uma série de atributos ao sujeito estigmatizado.

Construímos uma teoria do estigma; uma ideologia para explicar a sua inferioridade e dar conta do perigo que ela representa, racionalizando algumas vezes uma animosidade baseada em outras diferenças, tais como as de classe social. Utilizamos termos específicos de estigma como aleijado, bastardo, retardado, em nosso discurso diário como fonte de metáfora e representação, de maneira característica, sem pensar no seu significado original. (GOFFMAN, 1978, p. 8)

Sobre a população de rua recaem diversos estigmas. A perspectiva do vagabundo está relacionada com as ações desviantes ao trabalho, o que se expressa por meio de julgamentos morais colocando essas pessoas, como improdutivas, inúteis, preguiçosas e vadias. Na condição do louco é jogada a população de rua através do discurso biomédico, que a caracteriza como "doente mental”, anormal e que coloca a mendicância como um produto de "distúrbios da personalidade". São tidos como sujos, tanto quanto as ruas onde se dão as suas existências. A pecha do perigoso incide sobre essas pessoas pelo caminho do discurso jurídico e criminológico que relaciona a mendicância ao crime; ainda que essa lei não mais exista no Código Penal Brasileiro, seu conteúdo ainda permeia o imaginário social, reiterando o estigma. Como coitado dá lugar a práticas religiosas, nas quais o morador de rua é alvo de piedade. (NOGUEIRA, 2008)

A estigmatização e seus efeitos, tais como a discriminação, segregação, marginalização e exclusão, produzem reações na população dita "normal", tais como indiferença, aversão, medo, desrespeito, hostilidade, pressão para dispersão ou recolhimento pelos órgãos públicos, como também, tolerância, solidariedade e ajuda eventual e continua. (ESCOREL, 1999) A indiferença e o preconceito, conforme afirma Luiz Batista Soares (2009), produzem invisibilidade. Sobre a invisibilidade, Soares (2009, p. 331) diz: 
[...] a identidade só existe no espelho, e esse espelho é o olhar do outro, é o reconhecimento dos outros. É a generosidade do olhar do outro que nos devolve a nossa própria imagem ungida de valor [...] Nada somos e não valemos nada se não contarmos com o olhar alheio acolhedor, se não formos vistos, se o olhar do outro não nos recolher e salvar da invisibilidade - invisibilidade que nos anula e que é sinônimo, portanto, de solidão e incomunicabilidade, falta de sentido e valor.

Esta é outra marca importante da população em situação de rua. "Como não escolhem e não fazem as regras do mundo em que vivem” (ESCOREL, 1999, p. 236), não são tidos como “indivíduos” ou, quando reconhecidos como tal, são considerados "deslocados" e "fora do lugar"; isso corrobora com a ideia de Goffman (1978) de que o estigmatizado não se sente - ou não é visto como - completamente humanos.

Cabe ainda registrar que entre os principais atos desviantes produtores de estigmas atribuídos à população em situação de rua estão a privatização do espaço público e o uso de modalidades de sobrevivência que destoam em relação ao mundo do trabalho. A sobrevivência cotidiana dos moradores de rua é realizada em público o que, consoante Escorel (1999), transgride os princípios básicos de organização social que distinguem as esferas e atividades públicas daquelas que são colocadas na ordem do privado; em outras palavras, o que é próprio da rua e próprio da intimidade da casa. O que, de um modo geral, a sociedade entende como ação privada que não pode ser realizada em espaço público, os moradores de rua entendem como satisfação das necessidades vitais. DaMatta (1997) coloca que a oposição casa/ rua $^{3}$ é dinâmica e relativa. O ocupar a rua como espaço de moradia implica uma subversão de tal ordem que a ocupação define o ocupante. Ou seja, a rua é local de indesejável individualização, de luta e de malandragem e os que vivem ali são tidos como desviantes, marginais, meliantes. Ao realizar em público ações que seriam do âmbito do privado, o morador de rua

3 DaMatta (1997) utiliza em seus estudos casa erua como categorias sociológicas. A casa tal qual ele define, "é um espaço de calma, repouso, recuperação e hospitalidade, enfim, tudo aquilo que define a ideia de 'amor', 'carinho', 'calor'humano”. (DAMATTA, 1997, p. 57) Na casa o código fundamenta-se nas relações pessoais estabelecidas por laços familiares. Já a rua é um espaço definido como inverso, ou seja, como algo movimentado, propício a desgraças, semidesconhecido e semicontrolado, povoado pelo perigo. (DAMATTA, 1997) 
passa a ser marcado, identificado pelas características próprias da rua, tais como sujeira e periculosidade. Em relação ao trabalho, não se pode dizer de regularidade e continuidade, o que não permite o atendimento de suas necessidades no âmbito privado.

Em suma, a exclusão social e os estigmas atribuídos à população de rua em função de sua trajetória de vida são processos interligados. Ambos dificultam ou negam o acesso desses aos direitos mais básicos como moradia, saúde, educação, alimentação, etc.; e também pautam as ações direcionadas a esse grupo social, seja para construção de políticas públicas específicas, seja no que concerne às violações de direitos humanos vivenciadas diariamente. Em outras palavras, exclusão social, tanto quanto estigmas, atribuídos às pessoas que vivem parte de suas trajetórias de vida nas ruas são importantes motivadores das ações direcionadas a essa parcela da sociedade.

\section{CARIDADE PARA OS MERECEDORES E SALVAÇÃo PARA QUEM DOA COMIDA}

A busca por comida é um dos eixos centrais através dos quais a rotina na rua se constrói, estimulando os trajetos e deslocamentos dessas pessoas pela cidade e suas potenciais relações. (ESCOREL, 1999; FRANGELLA, 2004) Uma das formas mais comuns de acesso à alimentação se dá pelo que Escorel intitula de redes de sobrevivência que são compostas, em sua maioria, por entidades privadas religiosas que distribuem comida, roupas, prestam auxílio para retirada de documentos, para obtenção de assistência médica, etc. Essas redes são “parte crucial da 'mágica' da sobrevivência dos moradores de rua”. (ESCOREL, 1999, p. 229)

Reiterando os termos simbólicos em que as doações acontecem, a piedade apresenta-se como um dos principais motivadores para a ação de distribuição de comida nessas redes de sobrevivência, marcadamente, como majoritárias, entre as entidades religiosas. Tomemos a piedade como a capacidade de se ter compaixão pelo sofrimento alheio. (KARDEC, 2013) A partir deste sentimento é possível exercitar um dos principais preceitos do Cristianismo: o amor ao próximo, ou seja, fazer ao outro "[...] todo o bem que nos seja possível e que desejaríamos que nos fizessem”. (KARDEC, 2013, p. 379)

Tal como colocado, esse sentimento de piedade vem acompanhado de outro compromisso e dever cristão, a caridade; esta que, a partir de 
concepção cristã-ocidental, tem lugar como um conjunto de ações fundadas em valores como altruísmo e bondade, que objetivam dar aquilo que o outro necessita, seja de forma material, com as práticas de beneficência, isto é, práticas de distribuição de recursos materiais, seja de forma moral. (NEVES, 1999)

É interessante notar que o sentido de piedade e de caridade mudam a partir do entendimento de cada religião acerca de quem é o igual, o irmão, o merecedor de sua ajuda. Por exemplo, o advento do capitalismo e as transformações nos grandes centros urbanos decorrentes da Revolução Industrial e Agrícola acarretaram aumento significativo do número de pessoas empobrecidas, o que tornou a pobreza - e nessa condição, as pessoas em situação de rua - um problema social. A partir daí, as igrejas investem mais na criação de critérios que definiriam os deveres dos fieis frente à pobreza. Chama-se de caridade discriminatória ou seletiva essa interpretação cristã da caridade que a relaciona com o merecimento. (CASTEL, 1998; VISCARDI, 2011)

Nos discursos e práticas dessas instituições religiosas que distribuem comida e prestam outras assistências aos que vivem nas ruas, a questão da caridade discriminatória ou seletiva está presente. Os moradores de rua que frequentam instituições filantrópicas e de assistência social estatal, para sobreviver cotidianamente na rua, devem provar que merecem essa atenção, demonstrando sua passividade e não periculosidade. Segundo Neves (1999), o morador de rua precisa vestir a roupa de "bom pobre", para que seja merecedor daquela ação. Os próprios moradores de rua sabem o que precisam fazer e dominam as condutas “aceitas” por aqueles que doam os alimentos. E valem-se disso para percorrer determinados círculos de relação social.

Ainda nos espaços caritativos de doação de alimentos, a pessoa em situação de rua precisa seguir determinadas regras para conseguir a comida pretendida. O interesse em "civilizar" os moradores de rua surge nas regras para o merecimento da caridade produzida pela caridade seletiva, pela construção de regras de sociabilidade dentro do espaço de doações e pelas pregações e sermões feitos dentro de determinados preceitos religiosos.

As ações de distribuição de comida, seja na rua, seja nas instituições, muitas das vezes são acompanhadas por pregações religiosas, cujos temas, segundo Frangella (2004), são similares nos diferentes grupos. Em sua maioria, são baseados na perspectiva cristã ocidental; são poucos os grupos que seguem outras perspectivas religiosas e que fazem esse tipo de trabalho 
com a população em situação de rua. Mas, mesmo que o grupo não siga os preceitos cristãos, o entendimento das falas que acompanham o trabalho é similar, correspondendo a "[...] um convite ao exorcismo e, consequentemente, à mudança de vida”. (FRANGELLA, 2004, p. 229)

A comida aqui assume o papel de mote para a evangelização, esta que não aparece somente nas pregações, estando presente também nos atos sacros e ritos que envolvem tanto o preparo como o processo de distribuição da comida para os que vivem nas ruas. Segundo Silva e demais autores (2011), a eficácia da evangelização daqueles que vão aos serviços religiosos - seja nas instituições, seja na própria rua - é medida, não apenas pela efetiva conversão do morador de rua em determinada religião, mas também pelo próprio ato de evangelizar o outro e pelo efeito que isso produz: a garantia da sensação de dever cristão cumprido. Todos esses atos de caridade têm como objeto prioritário o merecedor que recebe a comida naquele momento; mas, também, têm como objetivo a salvação eterna daquele que faz a doação.

\section{ALIMENTAÇÃO E A CONSTRUÇÃO DE CORPOS DÓCEIS}

Jogos de força estão presentes no campo da Alimentação e Nutrição quando está em questão a comida distribuída para a população em situação de rua. Nesse microcosmo estão imersos os agentes sociais e as instituições produtoras, reprodutoras e transmissoras de saberes, práticas e modos de ser conformando uma rede, um conjunto de relações objetivas entre posições definidas a partir das diferentes posições ocupadas pelos atores num determinado arranjo na estrutura da distribuição das diferentes espécies de poder ou de capital. No campo religioso, diferentes lógicas regulam a atividade humana, produzindo os sentidos das ações humanas e os sujeitos, subjetividade. Diversos grupos religiosos que estabelecem relações entre si e com os demais, seguem produzindo, transmitindo e reforçando modos de sentir, agir e pensar que repercutem em cada indivíduo em particular e na própria comunidade. Modos de ser, agir e pensar, assimilados e repetidos através do habitus, ou seja, um sistema de disposições duradouras adquiridas pelo indivíduo durante o processo de socialização.

Nesse jogo, a comida distribuída pelas instituições religiosas corresponde a um importante capital simbólico. Ela assume um caráter divino, 
que se manifesta nos atos sacros e ritos religiosos que envolvem o processo de preparo, cocção e distribuição da mesma. Aí, a comida atende não só ao corpo físico, como também à alma, servindo como remédio para as dores da existência e ponto de apoio para aqueles que vivem em situação de rua. A título de ilustração: o Movimento de Amor ao Próximo (AOS OBREIROS..., 2018), em carta destinada aos obreiros das quentinhas, publicada em sua página na internet, coloca que junto à fome, aquela quentinha leva esperança aos “desditosos irmãos” (sic).

Ao realizar em público ações que, segundo as normas hegemônicas, seriam do âmbito privado, a população em situação de rua assume os status do local que ocupa. Se a rua é local da sujeira, da luta, da malandragem, os que ali vivem são tidos como sujos, perigosos, vagabundos, malandros. A população de rua funciona numa lógica diferente das referências culturais hegemônicas e, nesse sentido, as práticas de distribuição de comida a esse grupo social orientam-se pela expectativa de retorno e adequação desse grupo aos padrões sociais dominantes. Isso já está internalizado pelos moradores de rua, visto que, como observa Neves (1999), para conseguir a comida eles precisam demonstrar sua docilidade e não periculosidade. Para chamar a atenção dos doadores é necessário lançar mão de inúmeros recursos, comprovando, assim, que são merecedores daquela ajuda. Os moradores de rua dominam as condutas “aceitas” e valem-se disso para percorrer determinados círculos de doação de comida.

As práticas de distribuição de comida são ritualizadas e cheias de regras, assumindo um importante papel civilizatório desta população. As lógicas presentes no campo religioso são normatizadoras e esquadrinham as subjetividades desse grupo social, induzindo a produção de um sujeito de desejo assujeitado aos interesses dominantes. No jogo de forças, essa relação é ainda mais perversa, pois gera e mantém uma espécie de dependência da população em situação de rua a esses serviços visto que a comida ali oferecida é, em sua maioria, a única refeição que aquele indivíduo fez no dia.

Nessas ações, o discurso religioso da piedade e da caridade modela o estigma do coitado e a ação de distribuição de comida pode ser entendida como estruturada e estruturante de uma não valorização da autonomia da população em situação de rua. Essas práticas, em certa medida, tornam os corpos da população em situação de rua dóceis, um pouco mais disciplinados, encaixando-os em subjetividades predeterminadas, assujeitadas, adequadas 
às lógicas vigentes. Essas instituições, geralmente, não questionam as causas da desigualdade social e da exclusão que levam as pessoas para a rua, elas atuam apenas no sentido de mitigar as consequências e ocupar espaço no jogo político e social.

Sempre há lugar para as contingências; parece-nos, contudo, que o espaço para singularidades é bastante reduzido nessas condições em que praticamente não é possível escolher o que comer, nem o quanto comer ou onde comer e menos ainda quando comer. Tudo é previamente definido pelo doador, ficando as pessoas submetidas às condições e normas das instituições. Ainda assim, a comida é um importante catalisador de vínculos, solidariedade e agregação da população em situação de rua. (ESCOREL, 1999; FRANGELLA, 2004) Isso nos leva à reflexão de que o ato de distribuir a comida, apesar de imbricado ao estigma do coitado, torna-se uma importante ferramenta no combate às violências que a indiferença e a invisibilidade produzem.

Mas não podemos esquecer que a mesma comida que alimenta os corpos biológicos e sociais das pessoas que vivem em situação de rua, alimenta também os corpos institucionais dos grupos que promovem a doação, além de alimentar a alma, o corpo simbólico dos sujeitos que realizam a ação. $\mathrm{Na}$ mesma quentinha que é distribuída na rua cabem os nutrientes, os códigos sociais, os valores morais e a salvação espiritual. Cabe muita coisa numa simples quentinha de alumínio.

\section{REFERÊNCIAS}

AOS OBREIROS das quentinhas. Movimento amor ao próximo, Rio de Janeiro, 2018. Disponível em: http://www.map.org.br/blog/page/9/. Acesso em: 15 out. 2019.

ARENDT, H. A condição humana. Rio de Janeiro: Forense Universitária, 2007.

ARENDT, H. Origens do totalitarismo. São Paulo: Companhia das Letras, 1989.

BAREMBLIT, G. Compêndio de análise institucional e outras correntes: teoria e prática. Rio de Janeiro: Rosa dos Ventos, 1994.

BAUMAN, Z. Vidas desperdiçadas. Rio de Janeiro: Zahar, 2005.

BOURDIEU, P. O poder simbólico. Rio de Janeiro: Bertrand, 1989. 
BOVE, C.; FIGUEIREDO, G. A política nacional para a população em situação de rua: processo e participação. In: GRINOVER, A. P.; ASSAGR, G.; GUSTIN, M. et al. Direitos fundamentais das pessoas em situação de rua. Belo Horizonte: D’Plácido, 2014. p. 421-437.

CARVALHO, M.; LUZ, M.; PRADO, S. Comer, alimentar e nutrir: categorias analíticas no campo da pesquisa científica. Ciências e Saúde Coletiva, Rio de Janeiro, v. 16, n. 1, p. 155-163, 2011.

CASTEL, R. As metamorfoses da questão social. Petrópolis: Vozes, 1998.

CASTRO, E. Vocabulário de Foucault. 2. ed. Belo Horizonte: Autêntica, 2016.

CONTRERAS, J.; GRACIA, M. Alimentação, sociedade e cultura. Rio de Janeiro: Fiocruz, 2011.

DAMATTA, R. A casa e a rua: espaço, cidadania, mulher e morte no Brasil. Rio de Janeiro: Rocco, 1997.

ESCOREL, S. Vidas ao léu: trajetória de exclusão social. Rio de Janeiro: Fiocruz, 1999.

FOUCAULT, M. A hermenêutica do sujeito. São Paulo: Martins Fontes, 2004b.

FOUCAULT, M. Ditos e Escritos: ética, sexualidade e política. 3. ed. Rio de Janeiro: Forense Universitária, 2004a.

FOUCAULT, M. Ditos e Escritos: estratégia, poder-saber. Rio de Janeiro: Forense Universitária, 2012.

FOUCAULT, M. Em defesa da sociedade. São Paulo: Martins Fontes, 2002.

FOUCAULT, M. História da sexualidade: a vontade de saber. Rio de Janeiro: Graal, 1988.

FOUCAULT, M. Microfísica do poder. 8. ed. Rio de Janeiro: Graal, 1989.

FOUCAULT, M. Vigiar e punir: o nascimento das prisões. 35. ed. Petrópolis: Vozes, 2008.

FRANGELLA, S. M. Corpos urbanos errantes: uma etnografia da corporalidade de moradores de rua em São Paulo. 2004. Tese (Doutorado em Ciências Sociais) - Institutos de Filosofias e Ciências Humanas, Universidade Estadual Campinas, Campinas, 2004.

GOFFMAN, E. Estigma: notas sobre a manipulação da identidade deteriorada. Rio de Janeiro: Zahar, 1978.

GUATTARI, F.; ROLNIK, S. Micropolítica: cartografia do desejo. 12. ed. Petrópolis: Vozes, 2013.

KARDEC, A. O livro dos espíritos. Brasília, DF: FEB, 2013.

NAIFF, L. Exclusão social no contexto familiar: uma história de mulheres. In: OLIVEIRA, E. S.; GATTO, M. Programa de jovens mães: uma experiência do feminino. Rio de Janeiro: Imperial Novo Milênio, 2016. p. 19-41. 
NASSER, J. H. O que comem os excluídos? Os diferentes sentidos da comida oferecida para a População em Situação de Rua. 2018. Dissertação (Mestrado em Alimentação, Nutrição e Saúde) - Programa de Pós-graduação em Alimentação, Nutrição e Saúde, Instituto de Nutrição, Universidade do Estado do Rio de Janeiro, Rio de Janeiro, 2018.

NEVES, D. P. Os miseráveis e a ocupação dos espaços públicos. Caderno CRH, Salvador, n. 30-31, p. 111-134, 1999.

NOGUEIRA, F. D. Hóspedes incômodos: estudos sobre moradores de rua no hospital de emergência. 2008. Dissertação (Mestrado em Serviço Social) - Pontifícia Universidade Católica do Rio de Janeiro, Rio de Janeiro, 2008.

OKSALA, J. Como ler Foucault. Rio de Janeiro: Zahar, 2011.

PASTORAL da População de Rua. Arquidiocese de São Sebastião, Rio de Janeiro, 2014. Disponível em: http://arqrio.org/formacao/detalhes/443/pastoral-dapopulacao-de-rua. Acesso em: 3 dez. 2016.

REVEL, J. Dicionário de Foucault. Rio de Janeiro: Forense Universitária, 2011.

SILVA, J. K.; PRADO, S. D.; CARVALHO, M. C. et al. Alimentação e cultura como campo científico no Brasil.Physis: revista de saúde coletiva, Rio de Janeiro, v. 20, n. 2, p. 413-442, 2010.

SOARES, L. E. Juventude e violência no Brasil contemporâneo. In: MAIA, M. (org.). Por uma ética do cuidado. Rio de Janeiro: Garamond, 2009. p. 323-356.

VISCARDI, C. M. Pobreza e assistência no Rio de Janeiro na Primeira República. História, Ciência, Saúde, Rio de Janeiro, v. 18, n. 1, p. 179-197, 2011.

WEBER, M. Ação social e relação social. In: FORACCHI, M. M.; MARTINS, J. S. Sociologia e Sociedade: leituras de introdução à Sociologia. Rio de Janeiro: LTC, 1977. p. 139-144.

WEBER, M. Conceitos sociológicos fundamentais. Covilhã: Lusosofia, 2010.

WOLLZ, L. E.; LEITE, B. F.; FERREIRA, F. R. et al. Alimentação, cidadania e direitos da população em situação de rua: um tema ainda negligenciado. In: PRADO, S. D.; KRAEMER, F. B.; SEIXAS, C. M. et al. Alimentação e consumo de tecnologias. Curitiba: CRV, 2015. p. 434-451. 